\title{
Volitional component of the personality's psychological safety of physicians and their professional success
}

\author{
Anna Koteneva ${ }^{1, *}$, Anna Litvinova ${ }^{1}$, Aleksej Kokurin ${ }^{1}$ \\ ${ }^{1}$ Moscow State University of Psychology \& Education, Russia
}

\begin{abstract}
The article is devoted to the study of the features of the volitional component of the personality's psychological security and its impact on the professional success of extreme physicians. The results of the study of resuscitators and ambulance physicians ( 70 people, average age 47.9 years) show that a high level of volitional self-regulation is combined with such strong-willed qualities as perseverance, self-control, self-government, as well as self-control in various spheres of life. Professional success of physicians at the stage of "middle maturity" is characterized not only by a high level of development of personal, psychological and professional qualities, formed skills, effectiveness of medical manipulations, but also by high degree of self-efficacy in the fields of activity and interpersonal. The higher the level of volitional self-regulation of physicians, the higher the effectiveness of their activities according to expert assessments and selfefficacy in the field of activity. All physicians, regardless of the level of volitional self-regulation, have a high level of self-control in the emotional sphere and self-efficacy in the field of interpersonal relations, as well as well-formed professional skills and abilities.
\end{abstract}

\section{Introduction}

Professional success is an important indicator in the specialist assessment, as it reflects his desire to achieve acme in the profession and to realize his creative potential. The recognition of the human activities results by the professional community and colleagues satisfies the employee needs for self-actualization and self-identification. The social recognition instills self-confidence and encourages a specialist to solve socially significant problems in various spheres of life. The study of extreme profile physician's professional success is of particularly relevance and social significance. Extreme profile physicians, in particular emergency physicians and resuscitators, have to work in stressful conditions. There are various non-standard and extreme situations in physician's activity, which demand fast and responsible decisions under the conditions of time deficiency. Emergency medical care is the decisive factor in life saving of patients and victims, a condition for their quick recovery. The quality of activities of extreme profile physicians demand high responsibility and developed professionally important qualities, skills and abilities. Stressful situations of

\footnotetext{
* Corresponding author: akoteneva@yandex.ru
} 
physicians' work have negative impact on their psyche, lead to emotional burnout and reduce their professional success, violate the psychological security of the individual $[1,2,3,4]$.

Currently, the study of psychological factors of professional success of physicians is a socially significant problem. The goal of the healthcare reform being carried out in Russia is not only to increase the accessibility and quality of medical care for the general population, but also to improve the quality of professional training and retraining of personnel, the effectiveness and safety of their activities.

In modern psychology, professional success is considered as an important indicator in the assessment of a specialist, as it reflects his desire to achieve acme in the profession and realize his creative potential. The recognition by the professional community and colleagues of the results of a person's activity not only satisfies his meta-need for self-actualization and selfdetermination, instills confidence in his own strength, but also encourages a specialist to solve socially significant problems in various spheres of life.

The effectiveness of the physician's professional activities depends not only on the level of medical equipment of the institution, the implementation of new medical technologies, the sanitary and hygienic working conditions, the level of wages, but also on the psychological characteristics. One of the objective criteria of extreme profile physicians' professional success, alongside with their work efficiency (providing effective medical care to patients and victims), is the formation of professionally important qualities that ensure the solution of professional tasks under extreme conditions. Researchers distinguish between objective and subjective characteristics of professional success, i.e. the activities effectiveness, the specialist's status in social and professional spheres, the professionally important qualities and skills, the satisfaction with his position and the level of professional self-realization in vocational and interpersonal spheres of life. This is especially important for professionals at the stage of "middle maturity" (40-55 years), since this is not only the peak of life, the time of creative development and professional achievements, the desire to become a mentor, to transfer accumulated knowledge and skills, but also the time to reduce vital activity, collapse hopes and awareness of unrealized opportunities, violation of the psychological security of the individual [5].

For the successful implementation of activities in extreme conditions, a number of common psychological, physiological and physical qualities are needed. They include emotional-volitional, communicative and intellectual aspects of personality, which indicators must have high levels of development $[6,7]$. The individual volitional characteristics play a significant role in achieving the vocational goals and the activities regulation. The problem of personality investigation can be solved by studying volitional processes. The personality development is the mastering of one's own psyche and the expansion of psychological reality controlled by consciousness [8]. The strong-willed characteristics (self-control, selfregulation, self-management, composure, persistence) are the most important professional qualities necessary for a specialist to perform professional activities effectively at any stage and under extreme conditions [9]. Excessive professional workload in extreme situations faced by physicians (the patient's death, complications after operations, etc.) requires maximum awareness and self-regulation. The professional success is associated with the ability and the desire to set goals and to implement them in work. The abilities to emotionalvolitional self-regulation allow specialists to avoid mistakes in perception of emotional state in danger of extreme environmental influences.

Volitional regulation is one of the most important components of the psychological security of the personality $[10,11]$. The personality's psychological safety is considered as a state of protection of the human psyche from various influences, which are capable against his will and desire to change mental states, psychological characteristics of his activity and personality, impede social behavior and the formation of an adequate system of personal relations to the world and himself. The psychological security of the individual in a complex 
of phenomena (the need for security, sensation, experience and state of security, perceptions of security) is aimed at ensuring the integrity of a person, revealing the possibilities of his development as an active social subject, professional in conditions of interaction with the environment [12]. The will and mechanisms of volitional regulation allow the subject to consciously control the manifestations of external and internal factors that are significant for maintaining its vitality, resistance, defense from risks and threats, and the ability to continuous development in professional activity $[13,14]$.

The problem is that the influence of volitional characteristics of extreme profile physicians on their professional success is currently insufficiently studied. The purpose of this research is to study the professional success characteristic of extreme profile physicians with different levels of volitional self-regulation.

The hypothesis is that the strong-willed qualities are important for the physician's professional success: the higher the level of strong-willed self-regulation, persistence, composure and self-control in different spheres of activity, the higher the physician's selfefficacy and the effectiveness of his professional activities.

The following research objectives are set in the work: to identify the volitional characteristics and the qualities of professional success of extreme profile physicians with different levels of volitional self-regulation (1), to appreciate the relations between them (2).

\section{Methods}

\subsection{Participants}

The sample of the study involves Moscow resuscitation and emergency medical physicians, 70 persons ( 38 females and 32 males) in all. The average age of the respondents is 47.9 years. Five expert chief participants have the average work experience of 16.5 years and the average age of 48.0 years.

\subsection{Methods}

Three questionnaires "Volitional self-regulation" by A.V. Zverkova, E.V. Eydmana, "Capacity for self-management" by N.M. Peisakhova, "Revealing the severity of self-control in emotional sphere, activity and behavior" by G.S. Nikiforovoy, V.K. Vasilyeva and S.V. Firsova are used for the evaluation of volitional characteristics, i.e. perseverance, selfcontrol and volitional self-regulation.

Professional successfulness consists of the performance effectiveness and the selfefficacy of the specialist. The experts evaluate the activities effectiveness of physicians by a questionnaire "Physician's professional success" developed by A.V. Koteneva and N.V. Potapova. As criteria for assessing the external indicators of physician's professional success, i.e. the degree of formation of professionally important psychological qualities, knowledge, skills, abilities and a number of formal indicators (recovery, promotion and the number of operations) are used. The questionnaire provides a physician's assessment on seven indicators: personal qualities, professional motivation, psychological qualities, psychophysiological qualities, professional qualities, skills, additional merits of the employee. The indicator «Personal qualities» includes the following groups of qualities: proactive (responsible for himself), organized, punctual, confident, conscientious and persistent. The indicator «Professional motivation» consists of the desire to constantly learn in their professional activities (attend trainings, workshops, exhibitions, lectures), and the urge to achieve success. The indicator «Psychological qualities» contains the following qualities: empathic, tactful, firm in decision-making, able to stand for his point of view, 
altruistic. The indicator of «Physiological quality» are as following: balanced, fast response, and attentive. The indicator «Professional quality» includes: the ability to respond quickly to new situations and new requests, the ability to organize work, the desire for cleanliness and order in the workplace, responsibility, respect among colleagues and subordinates, and stress resistance. Indicator «Professional skills and knowledge» are as follows: knowledge of the human anatomical and physiological characteristics, awareness in clinical indicators, diagnostic abilities, the excellent possession of medical terminology and medical manipulations. Indicator "Additional merits of the physician» includes 'only successful operations' 'no complaints' and 'more than 7 encouragements' for the last year, more than 20 operations (carrying out or participation) for a month. The expert assesses each employee according to the degree of manifestation of each indicator with a 4-score reverse scale. It allows to determine the general level of professional success of the physician: 30-50 scores - a high level of success; 51-70 scores - an average level of success; 71-90 scores - a low level of success; more than 91 scores - very low level of success.

In the research two methods are used to assess the subjective component of professional successfulness. The questionnaire "Well-being in extreme conditions" by A. Volkova, N. Vodopyanova allows to identify the physician's psychophysical state and well-being, and the level of his psychological resistance to stressful conditions of work. "The Self-efficacy diagnosis test" by D. Maddux and M. Scheer is used to determine the degree of a specialist's self-efficacy in the field of vocational activities and in interpersonal communication.

The nonparametric Mann-Whitney criterion, Spearman rank correlation coefficient, conjugacy tables calculated in the IBM SPSS Statistics v program.20 are used for the analysis of the data obtained.

\section{Results}

\subsection{Qualities of strong-willed self-control of extreme profile physicians}

According to the results of the "Volitional self-regulation questionaire" by A.V. Zverkova, E.V. Eidman physicians are divided into three groups with the concern of different levels of volitional self-regulation: high, medium and low. The indicators of volitional characteristics of representatives of three groups and the significance of their differences due to MannyWhitney criterion are presented in tables 1 and 2.

Table 1. Indicators of physician's volitional characteristics in groups with different levels of volitional self-regulation.

\begin{tabular}{|c|c|c|c|c|c|c|}
\hline \multirow[t]{2}{*}{ Volitional characteristics } & \multicolumn{2}{|c|}{$\begin{array}{l}\text { Group 1: high level of } \\
\text { volitional self- } \\
\text { regulation }\end{array}$} & \multicolumn{2}{|c|}{$\begin{array}{l}\text { Group 2: medium } \\
\text { level of volitional } \\
\text { self-regulation }\end{array}$} & \multicolumn{2}{|c|}{$\begin{array}{l}\text { Group 3: low } \\
\text { level of } \\
\text { volitional self- } \\
\text { regulation }\end{array}$} \\
\hline & M & $\mathbf{S}$ & $\mathbf{M}$ & $\mathbf{S}$ & $\mathbf{M}$ & $\mathbf{S}$ \\
\hline \multicolumn{7}{|c|}{ "Volitional self-regulation questionaire"A.V. Zverkova. E.V. Eydmana } \\
\hline $\begin{array}{l}\text { General level of volitional self- } \\
\text { regulation }\end{array}$ & 16.9 & 2.2 & 11.2 & 1.1 & 6.9 & 1.3 \\
\hline Persistence & 9.6 & 2.5 & 6.1 & 1.04 & 3.7 & 1.2 \\
\hline Composure & 7.3 & 1.2 & 5.2 & 1.02 & 3.1 & 0.85 \\
\hline
\end{tabular}




\begin{tabular}{|l|c|c|c|c|c|c|c|}
\hline \multicolumn{7}{|c|}{ "Capacity for for self-management questionaire" by N.M. Peisakhova } \\
\hline Capacity for self-management & 33.7 & 7.8 & 27.1 & 9.1 & 23.4 & 10.6 \\
\hline $\begin{array}{l}\text { "Revealing the severity of self-control in emotional sphere. activity and behavior questionaire" by } \\
\text { G.S. Nikiforovoy. V.K. Vasilyeva and S.V. Firsova }\end{array}$ \\
\hline Overall level of self-control & 52.3 & 7.3 & 51.3 & 8.7 & 45.5 & 6.9 \\
\hline $\begin{array}{l}\text { Self-control in the emotional } \\
\text { sphere }\end{array}$ & 16.4 & 3.1 & 16.1 & 3.5 & 15.2 & 3.0 \\
\hline Self-control in activity & 18.3 & 3.1 & 18.0 & 5.7 & 15.7 & 4.6 \\
\hline Social self-control & 17.6 & 4.1 & 17.1 & 3.9 & 14.6 & 3.5 \\
\hline
\end{tabular}

The physicians of the first group ( $26 \%$ of all employees) with a high level of volitional self-regulation have a high level of development of persistence, composure, capacity for selfmanagement and self-control in different spheres of life. In the second group (48\% of all employees) with an average level of volitional self-regulation, physicians have an average level of persistence, composure and self-management and high rates of self-control in the emotional and social spheres and in the field of activity. The third group includes $26 \%$ of all physicians with a low level of volitional self-regulation, which is accompanied by a lower level of all other volitional indicators.

The application of the Mann-Whitney criterion reveals significant differences in the indicators of persistence and composure between all groups. That is, the higher the level of volitional self-regulation of physicians is, the more active, independent in their decisions, efficient they are, and the more they try to fulfill the planned actions, to demonstrate emotional stability and maturity, and self control in a variety of situations. Physicians of the first group differ significantly from physicians of other groups in more developed ability to self-management and the general level of self-control in the realization of various activities. Though there are no differences in these indicators between the second and third groups. Self-control in activity is equally expressed in the employees of the first and second groups, but significantly exceeds this indicator in the third group. There are no differences in the indicators of self-control in the emotional sphere, i.e. all physicians have a high level of formation of this quality.

Table 2. Empirical value of Mann-Whitney U- criterion when comparing volitional indicators.

\begin{tabular}{|c|c|c|c|}
\hline Group & $\begin{array}{c}\text { Group 1: high level of } \\
\text { volitional self- } \\
\text { regulation }\end{array}$ & $\begin{array}{c}\text { Group 2: medium level } \\
\text { of volitional self- } \\
\text { regulation }\end{array}$ & $\begin{array}{c}\text { Group 3: low level } \\
\text { of volitional self- } \\
\text { regulation }\end{array}$ \\
\hline \multicolumn{5}{|c|}{ "Volitional self-regulation questionaire" by A.V. Zverkova, E.V. Eydmana } \\
\hline \multicolumn{5}{|c|}{ General level of volitional self-regulation } \\
\hline Group 1 & - & $51,5^{* *}$ & $14,5^{* *}$ \\
\hline Group 2 & $51,5^{* *}$ & - & $138,5^{* *}$ \\
\hline Group 3 & $14,5^{* *}$ & $138,5^{* *}$ & - \\
\hline \multicolumn{4}{|c|}{ Persistence } \\
\hline Group 1 & - & $25,5^{* *}$ & 0 \\
\hline
\end{tabular}




\begin{tabular}{|c|c|c|c|}
\hline Group 2 & $25,5^{* *}$ & - & $50,5^{* *}$ \\
\hline Group 3 & $0 * *$ & $50,5^{* *}$ & - \\
\hline \multicolumn{4}{|c|}{ Composure } \\
\hline Group 1 & - & $54 * *$ & $0,5^{* *}$ \\
\hline Group 2 & $54 * *$ & - & $44^{* *}$ \\
\hline Group 3 & $0,5^{* *}$ & $44^{* *}$ & - \\
\hline \multicolumn{4}{|c|}{ "Capacity for for self-management questionaire" by N.M. Peisakhova } \\
\hline \multicolumn{4}{|c|}{ Capacity for self-management } \\
\hline Group 1 & - & $179 * *$ & $63^{* *}$ \\
\hline Group 2 & $179 * *$ & - & 254,5 \\
\hline Group 3 & $63 * *$ & 254,5 & - \\
\hline \multicolumn{4}{|c|}{$\begin{array}{l}\text { "Revealing the severity of self-control in emotional sphere, activity and behavior questionaire" by } \\
\text { G.S. Nikiforovoy, V.K. Vasilyeva and S.V. Firsova }\end{array}$} \\
\hline \multicolumn{4}{|c|}{ Overall level of self-control } \\
\hline Group 1 & $186^{*}$ & - & 230 \\
\hline Group 2 & $98,5^{*}$ & 230 & - \\
\hline Group 3 & 124 & 257,5 & - \\
\hline \multicolumn{4}{|c|}{ Self-control in the emotional sphere } \\
\hline Group 1 & - & 255,5 & $102 *$ \\
\hline Group 2 & 255,5 & - & 223 \\
\hline Group 3 & $102 *$ & 223 & - \\
\hline \multicolumn{4}{|c|}{ Social self-control } \\
\hline Group 1 & - & 291 & $93 *$ \\
\hline Group 2 & 291 & - & $192 *$ \\
\hline Group 3 & $93 *$ & $192 *$ & - \\
\hline
\end{tabular}

Note:* $-\mathrm{p}<0,05 ; * *-p<0,01$.

\subsection{Qualities of professional success of extreme profile physicians}

Professional success of physicians is evaluated by subjective and objective criteria. The indicators of well-being in extreme conditions, self-efficacy in the vocational and social activities are the subjective criteria of professional successfulness. The expert estimations of physician's professional success indicators are the objective criteria of their performance evaluation. Indicators of physician's professional success are presented by the degree of formation of professionally important personal, psychological and psychophysiological qualities, professional motivation, availability of professional knowledge, skills, abilities and 
a number of formal indicators (punishment, incentives and the number of operations). Descriptive statistics of subjective and objective indicators of physician's professional success in three groups are presented in table 3.

Table 3. Indicators of physicians professional success (descriptive statistics).

\begin{tabular}{|c|c|c|c|c|c|c|}
\hline \multirow[t]{2}{*}{ Professional success } & \multicolumn{2}{|c|}{$\begin{array}{l}\text { Group 1: high level } \\
\text { of volitional self- } \\
\text { regulation }\end{array}$} & \multicolumn{2}{|c|}{$\begin{array}{l}\text { Group 2: medium } \\
\text { level of volitional } \\
\text { self-regulation }\end{array}$} & \multicolumn{2}{|c|}{$\begin{array}{l}\text { Group 3: low level } \\
\text { of volitional self- } \\
\text { regulation }\end{array}$} \\
\hline & $\mathbf{M}$ & $\mathbf{S}$ & $\mathbf{M}$ & $\mathbf{S}$ & $\mathbf{M}$ & $\mathbf{S}$ \\
\hline \multicolumn{7}{|c|}{ Subjective indicators of professional success } \\
\hline \multicolumn{7}{|c|}{ "Well-being in extreme conditions questionaire" by A. Volkova. N. Vodopyanova } \\
\hline $\begin{array}{l}\text { General level of well-being in } \\
\text { extreme situations }\end{array}$ & 19.0 & 7.8 & 22.8 & 8.6 & 22.4 & 8.4 \\
\hline \multicolumn{7}{|c|}{ “Self-efficacy diagnosis test@ by D. Maddux and M. Scheer } \\
\hline $\begin{array}{l}\text { Self-efficacy in the subject } \\
\text { activity }\end{array}$ & 43.7 & 7.4 & 39.9 & 7.5 & 36.2 & 4.2 \\
\hline $\begin{array}{l}\text { Self-efficacy in interpersonal } \\
\text { relationships }\end{array}$ & 7.5 & 1.4 & 7.3 & 1.4 & 7.9 & 1.3 \\
\hline \multicolumn{7}{|c|}{ Expert evaluation of professional success of physicians } \\
\hline $\begin{array}{l}\text { General level of physicians } \\
\text { professional success }\end{array}$ & 39.1 & 6.7 & 62.5 & 16.1 & 75.4 & 11.7 \\
\hline
\end{tabular}

According to the results of "Well-being in extreme conditions" questionnaire by A. Volkova, N. Vodopyanova resuscitators and ambulance physicians in the sample have an average level of psychological resistance to extreme situations, satisfactory adaptation and well-being $(\mathrm{M}=21,71)$. Due to the Mann-Whitney U- criterion significant differences are present only between the first and third groups $(\mathrm{U}$ emp. $=119.5 ; \mathrm{p}=0.01)$, which allows to suggest that physicians with a higher level of volitional self-control have a higher level of adaptation to extreme situations. However, a certain trend is revealed when comparing these indicators between all groups. Table 4 shows the ratio of physicians (\%) with different levels of adaptation and well-being in the three groups.

Table 4. The ratio of physicians (\%) with different levels of adaptation and well-being in groups.

\begin{tabular}{|c|c|c|c|}
\hline Groups & $\begin{array}{c}\text { High level of } \\
\text { adaptation and } \\
\text { well-being }\end{array}$ & $\begin{array}{c}\text { Medium level of } \\
\text { adaptation and } \\
\text { well-being }\end{array}$ & $\begin{array}{c}\text { Low level of } \\
\text { adaptation and } \\
\text { well-being }\end{array}$ \\
\hline $\begin{array}{c}\text { Group 1: high level of volitional self- } \\
\text { regulation }\end{array}$ & $56 \%$ & $28 \%$ & $16 \%$ \\
\hline $\begin{array}{c}\text { Group 2: medium level of volitional } \\
\text { self-regulation }\end{array}$ & $26 \%$ & $42 \%$ & $32 \%$ \\
\hline $\begin{array}{c}\text { Group 3: low level of volitional self- } \\
\text { regulation }\end{array}$ & $17 \%$ & $61 \%$ & $22 \%$ \\
\hline
\end{tabular}


The analysis of the conjugacy table shows that with the increse of the level of volitional self-regulation the number of physicians with a high level of psychological stability and with the ability to maintain a good state of health increases, as well as the number of physicians with medium and low levels of psychological stability decreases.

According to the results of "Self-Efficacy Diagnosis Test" by D. Maddux and M. Scheer, the average estimation of self-efficacy in the general sample exceeds the normative values, that meens that specialists of all groups highly evaluate their professional potential both in the vocational area $(M=39.96)$ and in the interpersonal relations field $(M=7.24)$. However, the Mann-Whitney criterion allows to reveal significant differences between groups 1 and 3, indicating that physicians with a higher level of self-control have a higher level of selfefficacy in the vocational activities (Uemp. $=66.5 ; \mathrm{p}=0.01$ ). The indicators of self-efficacy in interpersonal relationships do not actually differ in the groups due to the Mann-Whitney Ucriterion. Physicians successfully manifest themselves in interpersonal relationships with colleagues and patients.

According to the expert evaluations professional success of physicians differs in three groups both in its level and in quality characteristics. Table 5 shows the percentage of physicians with different levels of professional success according to expert estimations.

Table 5. Ratio of physicians (\%) with different levels of professional success in groups according to expert estimates.

\begin{tabular}{|c|c|c|c|}
\hline Groups & $\begin{array}{c}\text { High level of } \\
\text { professional } \\
\text { success }\end{array}$ & $\begin{array}{c}\text { Medium level of } \\
\text { professional } \\
\text { success }\end{array}$ & $\begin{array}{c}\text { Low level of } \\
\text { professional } \\
\text { success }\end{array}$ \\
\hline $\begin{array}{c}\text { Group 1: high level of volitional } \\
\text { self-regulation }\end{array}$ & $94 \%$ & $6 \%$ & $0 \%$ \\
\hline $\begin{array}{c}\text { Group 2: medium level of } \\
\text { volitional self-regulation }\end{array}$ & $12 \%$ & $67 \%$ & $21 \%$ \\
\hline $\begin{array}{c}\text { Group 3: low level of volitional } \\
\text { self-regulation }\end{array}$ & $0 \%$ & $22 \%$ & $78 \%$ \\
\hline
\end{tabular}

The results show that the effectiveness of physician's activities with a high level of volitional self-regulation is almost twice as high as compared with physicians with a low level of the ability to arbitrarily regulate their behavior. Moreover, $94 \%$ of physicians with a high level of volitional regulation have the highest rates of professional success. As the level of strong-willed self-regulation decreases, the effectiveness of work first decreases to an average (67\%), and then to a low level (78\%).

Qualitative analysis of the physician's performance of each group on various criteria of professional success reveal some differences. Experts highly estimate the level of development of the necessary for work personal, psychological and professional qualities of physicians in the first group, the level of their motivation, well-developed skills, as well as many additional merits. According to experts evaluation the lower manifestations of professional success in the second group are associated with a decrease in professional motivation and the lack of additional merits. At the same time, experts highly esteem the degree of formation of personal, psychological and professional qualities, the high level of skills development of the representatives of this group. In group 3 the experts notice a decrease in the level of formation of personal, psychological and professional qualities of physicians while evaluating a high level of their professional motivation, professional skills and abilities.

Spearman rank correlation coefficients are calculated to analyze the relationship between volitional self-regulation and professional success. The results indicate the presence of 
significant correlations between indicators of volitional self-regulation and expert assessments of physician's professional success $(\mathrm{r}=0.642 ; \mathrm{p}=0.01)$, well being in extreme situations $(\mathrm{r}=0.31 ; \mathrm{p}=0.05)$, and self-efficacy in the vocational activities $(\mathrm{r}=0.389 ; \mathrm{p}=0.01)$.

\section{Discussion}

Volitional characteristics of extreme profile physicians with different levels of volitional selfregulation and their professional success are revealed. The characteristics of the formed volitional self-control are expressed abilities for volitional self-regulation, perseverance, selfcontrol, self-management, self-control in the emotional sphere, in activity and in the social sphere, ensuring the psychological safety of the individual. Similar results are obtained in the study of job performance quality of thermal power plants operational employees with various levels of professionalism. The authors show that the developed self-control is typical for the thermal power plants operational personnel regardless of their level of professionalism [9].

As shown by the results of this study the higher the level of volitional self-regulation is, the higher the levels of the indicators of professional self-efficacy and performance are. The same tendency is typical for specialists of other dangerous professions [7]. Thus, superprofessionals among the operational personnel of thermal power plants are characterized by a high level of strong-willed self-regulation, persistence and perseverance in comparison with professionals and pre-professionals. Strong-willed qualities insure professional and general reliability of a specialist. Due to the ability to self-regulation, persistence and self-control specialists retain mental stability in stressful situations [9]. Strong-willed control is associated not only with professional success, but also with success in other activities. R.M. Shamionov, M.V. Grigoryeva, A.V. Grigoryev show that the volitional qualities are the predictors of the importance of social activity of students [15].

The hypothesis "the higher the levels of strong-willed self-regulation, persistence, composure, and self-control in different spheres of activities, the higher the physicians selfefficacy and the effectiveness of their professional activities" is confirmed. Thus, training of resuscitators and emergency physicians should include ensuring the psychological safety of the person, the development of psychological, personal, professionally important qualities necessary for work in extreme situations.

\section{Conclusions}

Strong-willed self-control is a physician's professionally important quality. Thus, the high level volitional self-regulation indicates the formation of an effective holistic system of selfmanagement, which manifests itself in persistence, self-control in different spheres of life. At the same time, self-control in the emotional sphere is an absolute professionally important quality, in the absence of which it becomes impossible for extreme profile physicians to solve work problems. Self-control in the emotional sphere is necessary for the work performance at the minimum or average normative level. Physician's professional success includes both objective performance indicators and subjective ones, i.e. satisfaction with the state of health in stressful situations, realization of the potential in professional activities and in the sphere of interpersonal relations. Resuscitators and ambulance physician's professional success is characterized by a high level of development of personal, psychological and professional qualities, formed professional skills, effectiveness of medical manipulations, as well as by a high degree of self-efficacy in the vocational and interpersonal spheres. Strong-willed selfcontrol as a component of psychological security of the individual is a necessary condition for the physician's professional success because it is closely connected with the psychological 
stability and well-being in extreme situations, self-efficacy in the vocational activities and the professional problems solving effectiveness.

\section{Acknowledgement}

This research was supported by Russian Science Foundation № 19-18-00058.

\section{References}

1. K.A. Bochaver, A. Danilov, S.K. Nartova-Bochaver, A. Kvitchasty, O. Gavrilova, N. Zyazina, Clinical Psychology and Special Education 8(1), 58-77 (2019) doi:10.17759/cpse.2019080104

2. M. Korehova, A.G. Soloviev, M. Kirov, I. Novikova, Clinical Psychology and Special Education 8(2), 16-37 (2019) doi:10.17759/cpse.2019080202

3. K.Y. Chen, C.M. Yang, C.H. Lien, H.Y. Chiou, M.R. Lin, H.R. Chang, W.T. Chiu, Int. J. Med. Sci. 10(11), 1471-1478 (2013) doi:10.7150/ijms.6743

4. A. Misiołek, P. Gorczyca, H. Misiołek, Z. Gierlotka, Anaesthesiology Intensive Thrapy 46(3), 155-161 (2014) doi: 10.5603/AIT.2014.0028

5. K.V. Karpinskii, T.V. Gizhuk, N.V. Kiselnikova, Experimental Psychology (Russia) 13(1), 171-183 (2020) doi:10.17759/exppsy.2020130113

6. T.N. Kabanova, E.A. Pleshakova, A.A. Dubinsky, A.S. Vasilchenko, Psychology and Law 7(1), 89-105 (2017) doi:10.17759/psylaw.2017070108

7. A. Koteneva, A. Kokurin, V. Ekimova, A. Frolova, Psikhologicheskii zhurnal 41(1), 3144 (2020) DOI: 10.31857/S020595920007314-1

8. E.O. Smirnova, Cultural-Historical Psychology 11(3), 9-15 (2015) doi:10.17759/chp.2015110302

9. A.V. Koteneva, M.A. Vereshchagina, Russian Psychological Journal 15(4), 142-178 (2018) DOI: 10.21702/rpj.2018.4.7

10. E.P. Gutnik, Bulletin of Omsk University. Series "Psychology" 4, 31-34 (2018) DOI 10.25513/2410-6364.2018.4.31-34

11. M.M. Kubanova, P.V. Gavrilin, Scientific notes of the Russian State Social University 17.3(148), 5-13 (2018) DOI: 10.17922/2071-5323-2018-17-3-5-13

12. A. Litvinova, A. Kokurin, V. Ekimova, A. Koteneva, V. Pozdnyakov, Journal Behav. Sci. 10(1) (2020) doi: 10.3390 / bs 10010001

13. T.S. Pukhareva, Psychologist 2, 9-19 (2016) DOI: 10.7256/2409-8701.2016.2.19195

14. N.V. Andronova, Zh.G. Garanina, M.S. Ionova, N.V. Rezepova, Humanities: Actual problems of the humanities and education 19.3(47), 320-336 (2019) DOI: 10.15507/2078-9823.047.019.201903.320-336.

15. R.M. Shamionov, M.V. Grigoryeva, A.V. Grigoryev, Social Psychology and Society 10(1), 18-34 (2019) doi: 10.17759/sps.2019100102 